\title{
Changes in corneal thickness following vitreous surgery
}

This article was published in the following Dove Press journal:

Clinical Ophthalmology

9 August 2012

Number of times this article has been viewed

\section{Akira Watanabe \\ Tomohiro Shibata \\ Hirotsugu Takashina \\ Shumpei Ogawa \\ Hiroshi Tsuneoka \\ Department of Ophthalmology, \\ The Jikei University School of \\ Medicine, Tokyo, Japan}

Correspondence: Akira Watanabe Department of Ophthalmology, The Jikei University School of Medicine,

3-25-8 Nishi-shinbashi, Minato-ku

Tokyo, I05-846I, Japan

Tel +8 I 33433 I I I I

Fax +8I 33433 I 936

Email akirawa@jikei.ac.jp
Purpose: We investigated changes in corneal thickness following vitreous surgery and determined whether such changes can be used to evaluate the invasiveness of a vitrectomy.

Patients and methods: This retrospective, consecutive, comparative study examined 20 eyes that had undergone 23-gauge vitrectomy. Corneal thickness was measured prior to as well as following 1 week, 1 month, and 3 months after surgery. Measurements were performed at the center and at points $3 \mathrm{~mm}$ superior, inferior, nasal, and temporal to the center.

Results: Across the 20 cases, postoperative data showed a significant increase at 1 week after surgery at all points, but recovery to preoperative levels was evident only 1 month after surgery $(P<0.05$, paired $t$-test test). In the rhegmatogenous retinal detachment group $(\mathrm{n}=9)$, mean corneal thickness 1 week after vitrectomy showed a significant increase at all points, but had recovered to preoperative levels by 1 month. In the proliferative diabetic retinopathy group $(\mathrm{n}=5)$, mean corneal thickness at 1 week after vitrectomy showed a significant increase at central, inferior, and temporal points, but had recovered to preoperative levels by 1 month. In the epiretinal membrane group $(n=6)$, a significant difference in thickness was apparent only at the superior point between baseline and at 1 week, but had recovered to preoperative levels by 1 month. In all groups, no significant differences in thickness were apparent at any of the measurement points between preoperative measurements and at 3 months after surgery ( $P<0.05$, Wilcoxon signed-rank test).

Conclusions: Measurement of corneal thickness is useful for assessing the extent of surgical stress following vitrectomy.

Keywords: corneal thickness, vitrectomy, MIVS, invasiveness

\section{Introduction}

In recent years, microincision vitrectomy surgery using either a 25- or 23-gauge system has gained wide use in ophthalmic surgery because of its minimally invasive characteristics. ${ }^{1}$ Efforts to develop a useful method to evaluate the degree of invasion due to vitrectomy, postoperative visual recovery, ${ }^{2}$ corneal endothelial cell count, ${ }^{3}$ and corneal shape ${ }^{4}$ are currently under investigation. However, criteria for evaluating the surgical invasiveness of vitrectomy have yet to be established.

Various biometric devices are currently available for the measurement of corneal thickness, and some even measure parts of the cornea besides the center. A change in corneal thickness is considered a useful indicator of corneal endothelial function. ${ }^{5-7}$ In particular, such changes are used to evaluate invasion due to cataract surgery, which involves anterior chamber procedures. Following cataract surgery, corneal thickness increases transiently before gradually recovering to the preoperative level. 
The present study investigated changes in corneal thickness following vitreous surgery and determined whether such changes can be used to evaluate the invasiveness of vitrectomy.

\section{Methods and subjects}

This study was designed as a retrospective, consecutive, comparative study. All study protocols were approved by the ethics committee of the Jikei University School of Medicine.

We studied 20 eyes in 20 patients who had undergone 23-gauge transconjunctival vitrectomy for epiretinal membrane (ERM) (six eyes), rhegmatogenous retinal detachment (RRD) (nine eyes), or proliferative diabetic retinopathy (PDR) (five eyes). All vitrectomies had been performed by the same experienced surgeon at Jikei University Hospital. Patients were comprised of 12 men and eight women with a mean age of 55.7 years (range, 22-82 years). Seventeen eyes had previously undergone insertion of an intraocular lens and three eyes were phakic. The ERM group was comprised of three men and three women (mean age, 68.7 years; range, 59-82 years); the RRD group was comprised of six men and three women (mean age, 56.9 years; range, 22-67 years); and the PDR group was comprised of three men and two women (mean age, 55.8 years; range, 35-75 years). Corneal thickness was measured using a Pentacam ${ }^{\circledR}$ anterior segment analyzer (OCULUS Optikgerate Gmbh, Wetzlar, Germany) before and at 1 week, 1 month, and 3 months after surgery. Measurement was performed at the center of the cornea, as well as at points $3 \mathrm{~mm}$ superior, inferior, nasal, and temporal to the center. Measurement of the corneal endothelial cell count using a specular microscope was performed before surgery and at more than 3 months after surgery.

We used the 23-gauge system for the surgical procedure, and we also used a floating lens and irrigating hand-held lens system for fundus observation. In the RRD group, core vitrectomy, peripheral vitrectomy with scleral depression around the entire circumference, internal drainage, and laser photocoagulation around tears were performed during surgery. After surgery, patients took a facedown position for 1-5 days. In the ERM group, core vitrectomy, peripheral vitrectomy with scleral depression around the three ports, and ERM peeling were performed. In the PDR group, core vitrectomy, peripheral vitrectomy with scleral depression around the entire circumference, and additional laser photocoagulation around the entire circumference were performed.
Across all 20 cases, mean ( \pm standard deviation) total surgery time was $60.1 \pm 25.6 \mathrm{~min}$ (range, $40-120 \mathrm{~min}$ ). When examining the groups individually, mean total surgery time was $46.7 \pm 6.8 \mathrm{~min}$ (range, $40-60 \mathrm{~min}$ ) in the ERM group; $78.1 \pm 28.2 \mathrm{~min}$ (range, $40-120 \mathrm{~min}$ ) in the RRD group; and $54.0 \pm 14.1 \mathrm{~min}$ (range, 40-90 $\mathrm{min}$ ) in the PDR group.

After surgery, patients were prescribed eye drops containing $0.5 \%$ levofloxacin hydrate and $0.1 \%$ dexamethasone sodium phosphate for 4 weeks, followed by eye drops containing $0.5 \%$ levofloxacin hydrate and $0.1 \%$ fluorometholone, which were to be administered until 3 months after surgery.

We excluded all cases in which corneal epithelium removal had been performed during vitrectomy, postoperative corneal epithelium damage or high intraocular pressure $>30 \mathrm{mmHg}$ had been detected, or where intraocular surgery had been performed within 1 year before vitreous surgery.

The present study investigated changes in mean corneal thickness following vitreous surgery in all cases, and assessed whether differences in mean corneal thickness change following vitreous surgery were seen between the ERM, $\mathrm{RRD}$, and PDR groups.

\section{Results}

Tables 1-4 summarize mean and standard deviations of corneal thickness before and at 1 week, 1 month, and 3 months after surgery in all cases. Moreover, the tables also summarize corneal thickness at the center and at the points $3 \mathrm{~mm}$ superior, inferior, nasal, and temporal to the center across the ERM, RRD, and PDR groups.

In all cases, postoperative data at all points showed a significant increase in corneal thickness at 1 week after surgery when compared with preoperative measurements,

Table I Changes in corneal thickness in all cases (mean \pm SD, $\mu \mathrm{m}$ )

\begin{tabular}{lllll}
\hline & Before & I week* & I month & 3 months \\
\hline Center & $571.6 \pm 36.1$ & $596.2 \pm 66.0^{*}$ & $572.5 \pm 37.3$ & $567.0 \pm 38.7$ \\
& & $P=0.008$ & $P=0.819$ & $P=0.228$ \\
Superior & $675.1 \pm 46.6$ & $706.8 \pm 69.5^{*}$ & $678.8 \pm 48.1$ & $668.3 \pm 54.2$ \\
& & $P=0.00 \mathrm{I}$ & $P=0.444$ & $P=0.288$ \\
Inferior & $658.6 \pm 45.6$ & $679.0 \pm 66.0^{*}$ & $663.3 \pm 45.4$ & $662.9 \pm 48.6$ \\
& & $P=0.036$ & $P=0.432$ & $P=0.569$ \\
Nasal & $658.7 \pm 36.0$ & $680.0 \pm 61.7^{*}$ & $661.6 \pm 42.5$ & $654.9 \pm 39.4$ \\
& & $P=0.024$ & $P=0.595$ & $P=0.473$ \\
Temporal & $632.5 \pm 39.6$ & $663.6 \pm 64.7^{*}$ & $635.8 \pm 36.2$ & $628.2 \pm 36.2$ \\
& & $P=0.005$ & $P=0.621$ & $P=0.488$ \\
\hline
\end{tabular}

Note: *A significant increase compared with preoperative measurement $(P<0.05$, paired-t-test test).

Abbreviations: Before, before vitrectomy; I week, I week after vitrectomy; I month, I month after vitrectomy; 3 months, 3 months after vitrectomy. 
Table 2 Changes in corneal thickness (mean \pm SD, $\mu \mathrm{m}$ ) RRD group

\begin{tabular}{lllll}
\hline & Before & I week* & I month & 3 months \\
\hline Center & $574.7 \pm 47.6$ & $620.8 \pm 89.7^{*}$ & $570.8 \pm 47.0$ & $565.9 \pm 48.3$ \\
& & $P=0.011$ & $P=0.155$ & $P=0.139$ \\
Superior & $684.3 \pm 48.8$ & $732.1 \pm 87.4^{*}$ & $674.2 \pm 49.1$ & $665.0 \pm 60.5$ \\
& & $P=0.015$ & $P=0.173$ & $P=0.123$ \\
Inferior & $664.7 \pm 51.2$ & $713.9 \pm 84 . I^{*}$ & $668.6 \pm 42.4$ & $666.7 \pm 45.5$ \\
& & $P=0.0381$ & $P=0.434$ & $P=0.593$ \\
Nasal & $651.9 \pm 39.1$ & $697.3 \pm 81.3^{*}$ & $647.0 \pm 40.7$ & $646.6 \pm 42.3$ \\
& & $P=0.028$ & $P=0.214$ & $P=0.529$ \\
Temporal & $645.3 \pm 44.1$ & $684.6 \pm 77.8^{*}$ & $637.9 \pm 38.3$ & $629.3 \pm 42.0$ \\
& & $P=0.038$ & $P=0.342$ & $P=0.138$ \\
\hline
\end{tabular}

Note: *A significant increase compared with preoperative measurement $(P<0.05$, Wilcoxon signed-rank test).

Abbreviations: RRD, rhegmatogenous retinal detachment; Before, before vitrectomy; I week, I week after vitrectomy; I month, I month after vitrectomy; 3 months, 3 months after vitrectomy.

and corneal thickness had recovered to preoperative levels by 1 month. No significant differences in thickness were apparent at any of the measurement points between preoperative measurements and at 3 months after surgery $(P>0.05$, paired $t$-test test) (Table1).

In the RRD group, mean corneal thickness at 1 week after vitrectomy showed a significant increase to preoperative levels at all points, but had recovered to preoperative levels by 1 month. No significant differences in thickness were apparent at any of the measurement points between the preoperative measurements and at 3 months after surgery $(P<0.05$, Wilcoxon signed-rank test) (Table 2).

In the PDR groups, mean corneal thickness at 1 week after vitrectomy showed a significant increase to preoperative levels at the center, inferior and temporal points, but had recovered to preoperative levels by 1 month. No signifi-

Table 3 Changes in corneal thickness (mean \pm SD, $\mu \mathrm{m}$ ) PDR group

\begin{tabular}{lllll}
\hline & Before & I week & I month & 3 months \\
\hline Center & $566.8 \pm 31.3$ & $581.8 \pm 31.6^{*}$ & $578.4 \pm 36.7$ & $572.6 \pm 44.7$ \\
& & $P=0.043$ & $P=0.224$ & $P=0.500$ \\
Superior & $689.4 \pm 32.1$ & $704.8 \pm 28.8$ & $715.5 \pm 40.3$ & $699.8 \pm 53.2$ \\
& & $P=0.138$ & $P=0.093$ & $P=0.343$ \\
Inferior & $663.0 \pm 36.1$ & $680.2 \pm 49 . I^{*}$ & $668.0 \pm 54.2$ & $675.2 \pm 57.5$ \\
& & $P=0.043$ & $P=0.685$ & $P=0.500$ \\
Nasal & $677.6 \pm 27.6$ & $683.8 \pm 33.3$ & $687.8 \pm 41.3$ & $677.8 \pm 44.0$ \\
& & $P=0.225$ & $P=0.345$ & $P=0.892$ \\
Temporal & $616.0 \pm 36.4$ & $652.0 \pm 42.3 *$ & $630.6 \pm 42.6$ & $627.4 \pm 38.6$ \\
& & $P=0.043$ & $P=0.500$ & $P=0.225$ \\
\hline
\end{tabular}

Note: *A significant increase compared with preoperative measurement $(P<0.05$, Wilcoxon signed-rank test).

Abbreviations: PDR, proliferative diabetic retinopathy; Before, before vitrectomy; I week, I week after vitrectomy; I month, I month after vitrectomy; 3 months, 3 months after vitrectomy.
Table 4 Changes in corneal thickness (mean \pm SD, $\mu \mathrm{m}$ ) ERM group

\begin{tabular}{lllll}
\hline & Before & I week & I month & 3 months \\
\hline Center & $571.0 \pm 26.1$ & $571.2 \pm 30.7$ & $570.0 \pm 25.9$ & $568.0 \pm 20.2$ \\
& & $P=0.916$ & $P=1.000$ & $P=0.249$ \\
Superior & $649.2 \pm 45.4$ & $657.3 \pm 54.8^{*}$ & $651.3 \pm 47.2$ & $647.7 \pm 43.3$ \\
& & $P=0.027$ & $P=0.086$ & $P=0.345$ \\
Inferior & \multirow{2}{*}{$657.2 \pm 44.4$} & $656.8 \pm 44.0$ & $667.8 \pm 49.2$ & $659.0 \pm 56.2$ \\
& & $P=0.463$ & $P=0.529$ & $P=0.345$ \\
Nasal & \multirow{2}{*}{$653.2 \pm 37.2$} & $650.8 \pm 37.8$ & $661.7 \pm 42.1$ & $648.2 \pm 28.1$ \\
& & $P=0.916$ & $P=0.249$ & $P=0.463$ \\
Temporal & \multirow{2}{*}{$627.0 \pm 34.5$} & $645.2 \pm 52.2$ & $637.0 \pm 32.8$ & $627.0 \pm 30.7$ \\
& & $P=0.345$ & $P=0.529$ & $P=0.917$ \\
\hline
\end{tabular}

Note: *A significant increase compared with preoperative measurement $(P<0.05$, Wilcoxon signed-rank test).

Abbreviations: ERM, epiretinal membrane; Before, before vitrectomy; I week, I week after vitrectomy; I month, I month after vitrectomy; 3 months, 3 months after vitrectomy.

cant differences in thickness were apparent at any of the measurement points between preoperative measurements and at 3 months after surgery $(P<0.05$, Wilcoxon signedrank test) (Table 3).

In the ERM group, a significant difference in corneal thickness was apparent only at the superior point between baseline and at 1 week, but had recovered to preoperative levels by 1 month. No significant differences in thickness were apparent at any of the measurement points between preoperative measurements and at 3 months after surgery $(P<0.05$, Wilcoxon signed-rank test) (Table 4).

Mean corneal endothelial cell count was $2784 \pm 246$ preoperatively, and $2751 \pm 288$ at more than 3 months after surgery.

\section{Discussion}

Transconjunctival microincision vitrectomy surgery using a 23- or 25-gauge system is considered to be minimally invasive when compared with the conventional 20 -gauge vitrectomy system. ${ }^{1,2,4}$ This is reportedly due to faster visual recovery ${ }^{2}$ and a reduced impact on corneal shape. ${ }^{4}$ However, little research has been conducted to compare postoperative intraocular inflammation levels between the two surgical procedures. $^{8}$

Visual acuity, anterior chamber flare and cells, postoperative refractive error, refraction change, induced astigmatism, and corneal thickness have been used as indicators of invasiveness in cataract surgery. Among these, corneal thickness is considered useful for evaluating the degree of corneal endothelial dysfunction due to anterior chamber procedures during cataract surgery or postoperative intraocular inflammation. ${ }^{5-7}$ Vitreous surgery does not generally involve 
an anterior chamber procedure, but anterior chamber flare and cells are still observed after vitreous surgery. ${ }^{9}$

Few studies have described postoperative changes in corneal thickness following vitreous surgery..$^{10}$ Our results demonstrate that, compared with preoperative values, postoperative corneal thicknesses at all points were significantly increased 1 week after surgery, but were not significantly different from preoperative levels by 1 month after surgery, at least in terms of means for all cases.

As with cataract surgery, corneal thickness following vitrectomy without an anterior chamber procedure increased transiently before recovering to preoperative levels. Mean corneal endothelial cell count did not decrease after vitreous surgery. Given these findings, the change in corneal thickness following vitreous surgery was attributed to the functional decline of the corneal endothelial cells due to inflammation caused by the surgery.

When comparing the different groups, mean corneal thickness at 1 week after vitrectomy showed a significant increase to preoperative levels at all points in the RRD group, but the ERM group showed a significant increase in corneal thickness only at the superior point at 1 week. In the RRD group, core vitrectomy, peripheral vitrectomy with scleral depression around the entire circumference, internal drainage, and laser photocoagulation around retinal tears were performed during surgery. In addition, patients maintained a facedown position for 1-5 days following surgery. In the ERM group, core vitrectomy, peripheral vitrectomy with scleral depression around the three ports, and ERM peeling were performed. In the PDR group, core vitrectomy, peripheral vitrectomy with scleral depression around the entire circumference, and additional laser photocoagulation around the entire circumference were performed. Mean total surgery time was longest in the RRD group and shortest in the ERM group.

Given the process and the duration of the vitreous surgery, it was suspected that the level of invasiveness would be highest in the RRD group. This suggests that an increase in corneal thickness is affected by the degree of invasiveness of the vitrectomy. This in turn suggests that an increase in corneal thickness is affected by the degree of inflammation of the anterior chamber after vitrectomy.

Clinical Ophthalmology

\section{Publish your work in this journal}

Clinical Ophthalmology is an international, peer-reviewed journal covering all subspecialties within ophthalmology. Key topics include: Optometry; Visual science; Pharmacology and drug therapy in eye diseases; Basic Sciences; Primary and Secondary eye care; Patient Safety and Quality of Care Improvements. This journal is indexed on Submit your manuscript here: http://www.dovepress.com/clinical-ophthalmology-journal
Given the retrospective nature of the present study, future prospective studies are required. The number of cases investigated in the present study was small, and future studies must be rigorous and consistent in terms of examining patients with specific underlying disease characteristics, and by regulating the surgical procedures used across all patients.

Corneal thickness can be measured using an anterior segment analyzer or by anterior optical coherence tomography. Such instruments are useful not only for evaluating corneal shape, but also for clarifying the invasiveness of vitreous surgery.

\section{Disclosure}

The authors report no conflicts of interest in this work.

\section{References}

1. Rizzo S, Genovesi-Ebert F, Murri S, et al. 25-gauge, sutureless vitrectomy and standard 20-gauge pars plana vitrectomy in idiopathic epiretinal membrane surgery: a comparative pilot study. Graefes Arch Clin Exp Ophthalmol. 2006;244(4):472-479.

2. Kadonosono K, Yamakawa T, Uchio E, Yanagi Y, Tamaki Y, Araie M. Comparison of visual function after epiretinal membrane removal by 20-gauge and 25-gauge vitrectomy. Am J Ophthalmol. 2006;142(3): 513-515.

3. Mitamura Y, Takeuchi S, Kasai H, Yamamoto S, Matsumura S, Kudou H. Corneal endothelial cell damage associated with pars plana vitrectomy. Nihon Ganka Gakkai Zasshi. 1998;102(1):59-63.

4. Okamoto F, Okamoto C, Sakata N, et al. Changes in corneal topography after 25 -gauge transconjunctival sutureless vitrectomy versus after 20-gauge standard vitrectomy. Ophthalmology. 2007;114(12): 2138-2141.

5. Behndig A, Lundberg B. Transient corneal edema after phacoemulsification: comparison of 3 viscoelastic regimens. J Cataract Refract Surg. 2002;28(9):1551-1556.

6. Suzuki H, Takahashi H, Hori J, Hiraoka M, Igarashi T, Shiwa T. Phacoemulsification associated corneal damage evaluated by corneal volume. Am J Ophthalmol. 2006;142(3):525-528.

7. Lundberg B, Jonsson M, Behndig A. Postoperative corneal swelling correlates strongly to corneal endothelial cell loss after phacoemulsification cataract surgery. Am J Ophthalmol. 2005;139(6): 1035-1041.

8. Inoue Y, Kadonosono K, Yamakawa T, et al. Surgically-induced inflammation with 20-, 23-, and 25-gauge vitrectomy systems: an experimental study. Retina. 2009;29(4):477-480.

9. Tachi N, Kondo M, Uchida H, Ogino N. Anterior chamber inflammation after vitrectomy in posterior vitreous membrane syndrome and phacoemulsification and intraocular lens implantation and intraocular lens implantation. Nihon Ganka Gakkai Zasshi. 1995;99(3):329-335.

10. Hager A, Loge K, Kutschan A, Wiegand W. The effect of cataract and vitreoretinal surgery on central corneal thickness and corneal hysteresis. Klin Monbl Augenheilkd. 2008;225(3):207-211.

\section{Dovepress}

PubMed Central and CAS, and is the official journal of The Society of Clinical Ophthalmology (SCO). The manuscript management system is completely online and includes a very quick and fair peer-review system, which is all easy to use. Visit http://www.dovepress.com/ testimonials.php to read real quotes from published authors. 